\title{
Language Learning Strategies in Kuwait: Links to Gender, Language Level, and Culture in a Hybrid Context
}

\author{
Mervat Abou Baker El-Dib \\ Zagazig University-Benha
}

\begin{abstract}
The present study revisits the link between culture, gender, language level, and learner's choice of language learning strategies. This is done by answering three questions: (1) what are the major Strategy Inventory of Language Learning (SILL) factors in Kuwait (a hybrid context)? (2) Which factors are related to gender? And (3) which factors are related to language level? The results of the study indicate a relationship between gender and active naturalistic language use, cognitive-compensatory strategies and repetition-revision strategies. They also indicate a relationship between language level and active naturalistic strategies and affective strategies. Based on these results, it is proposed that learning contexts in a cultural milieu are perhaps the strongest variable affecting strategy choice. Finally, proposals are made for a more contextualized approach to strategy research.
\end{abstract}

\section{Introduction}

The proliferation of research into language strategies in recent years has been perhaps due to the appealing promises such research carries to all parties involved in the business of teaching and learning foreign or second languages. Research promises learners ways that would lead them to success in achieving their goal of learning a target language (Oxford, 1990). It promises teachers ways that would help them in shifting the responsibility of their students' success off their shoulders onto those of their students (Holec, 1987). Moreover, it promises administrators a path to the success of their language courses (Oxford \& Burry-Stock, 1995).

Reaching generalizations, however, regarding the relationship between learning strategies and a multitude of variables has not been achieved. Ambitious attempts have been made to relate certain learning strategies to gender, age, proficiency, ethnicity, and styles. Generalizations have been made about the tendency of females to report using more strategies than males, proficient students using strategies more than less proficient ones, certain cultures promoting the use of particular strategies more than others, and certain learning styles leading to the use of certain strategies (Grainger, 1997; Kaylani, 1996; Oxford, 1989, 1996).

We are, however, still a long way from making such generalizations with any degree of certainty. This is perhaps due to contradictory findings and unresolved discrepancies in each of these areas, as well as lack of replication studies. Consequently, calls continue to be made for more studies in these areas in order to ascertain these findings and resolve the discrepancies.

The present study came in response to appeals made for continuous investigations of strategies in relationship to culture. Kuwait is a hybrid context (El-Dib, 1999b) which Green and Oxford (1995) defined as a context which "fits neither the description of a second language setting nor that of a foreign language environment." (p. 268) The cosmopolitan nature of the

Mervat Abou Baker El-Dib (EdD, Columbia University) is Associate Professor of Curricula and Instruction (TEFL) at Faculty of Education, Zagazig University, Benha, Egypt. 
population in Kuwait makes it a unique context where different nationalities of different first languages share English as a means of communication. English is the country's official second language. It is the language commonly used in banking, investment, and academic communities (Kuwait Information Office, 2002).

English input is readily available for those nationalities as well as for learners who wish to learn the language. Street signs, shops' names, advertisements of famous food stores such as "Kentucky Fried Chicken" are both in Arabic and in English (U.S. Commercial Service, 2003). Kuwaitis use English not only for study purposes, but also as a necessary means of communication between them and the mixed workforce living in Kuwait, the majority of which are unable to speak Arabic (Library of Congress Country Studies, 1993).

Participants in this study were a sample drawn from a large student population studying in the colleges of the Public Authority of Applied Education and Training (PAAET), a leading educational institution in Kuwait. Students in these colleges study English-for-special-purposes (ESP). Consequently, the "academic" English required from them in their college studies differed from the English required from them in their everyday lives. The different demands of the two contexts may have influenced the strategies they used in learning English.

This study presents a description of the strategy factors of Kuwaiti male and female students in two class levels. The results will then be discussed in relationship to other studies conducting factor analysis of the Strategy Inventory of Language Learning (SILL). The drawbacks of strategy research relying on questionnaires will be discussed and implications for future research will be presented.

\section{Review of Literature}

In 1995, Oxford and Burry-Stock conducted a large metaanalysis comparing the factor structures of six sets of data from Puerto Rico, Taiwan, China, Japan, Egypt, and the United States. The two purposes of the meta-analysis were to support the SILL as a valid and reliable research tool and to relate using certain learning strategies to certain cultures. In their quest for universality of certain strategies and the uniqueness of others in certain cultures, Oxford and BurryStock reported that for most samples, from different countries, more than one half of language learning strategy use is represented by the items on the SILL factors.

The results of factor analysis of these sets of data were compared maintaining the similarities and the discrepancies among cultures. It was found that a factor entitled "active naturalistic language use" explains the most variance in Puerto Rico (a hybrid context), China, Japan, and the United States. This factor included strategies: $(\# 11)^{1}$ I try to talk like native English speakers, (\#13) I use English words I know in different ways, (\#14) I start conversations in English, (\#15) I watch TV and movies in English, (\#16) I read for pleasure, (\#17) I write notes, letters, reports in English, (\#35) I look for people I can talk to in English, (49) I ask questions in English, and (\#50) I try to learn about the culture of English speakers.

A different factor explained the most variance in Taiwan and Egypt. The factor called "metacognitive planning" comprised the variables: (\#34) planning the schedule, (\#36) looking for reading opportunities, (\#37) having clear goals, (\#38) thinking about progress, (\#8) reviewing often, (\#23) making summaries, (\#14) looking for conversation partners, (\#33) trying to find better ways to learn English, and (\#31) noticing mistakes to learn better.

This study was an attempt to provide another set of data from the Arabian Gulf area to find out which factors are operating in Kuwait and whether or not they are the same as the ones found in Puerto Rico, Taiwan, China, Japan, Egypt, and the United States. In addition, the study focused on three variables that have been tied to the choice of learning strategies: gender, language level, and ethnicity (Grainger, 1997; Oxford, 1989).

\section{Language Learning Strategies and Gender}

The results of research into gender differences in the use of language learning strategies have been contradictory at best. Whereas some studies asserted the existence of differences (Kaylani, 1996; Oxford, Park-Oh, Ito, and Sumrall, 1993) others maintained their absence (El-Dib, 1999a; Vandergrift, 1997). There were no differences between Kuwaiti males and females in their use of the six categories of strategies, yet there were differences at the level of individual strategies (El-Dib, 1999a). Interestingly, Oxford (1996), a main advocate of gender differences in strategy use, considered the possibility that differences found in some studies might be due to the fact that "males and females are different in how they report their strategies retrospectively but are not in reality all that different when they actually use strategies." (p. 248)

The relationship between gender and choice of learning strategies continues to be the most controversial. Opponents and proponents of research into gender differences are still debating the consequences, limitations and promises of this research direction (El-Dib, 1999a; Goviet, 1998; Politzer, 1983). Still it remains an issue of importance since men and women are being raised and educated differently in different cultures.

\section{Language Learning Strategies and Language Level}

Research has shown a positive relationship between proficiency and strategy use. Green and Oxford (1995) found that the proficiency level significantly affected the use of compensation, cognitive, metacognitive, and social strategies, but displayed no effect on the use of memory and affective strategies. Oxford and Burry-Stock (1995), in their 
large metastudy comparing the factor structures of six sets of English-as-a-second-language (ESL)/English-as-a-foreign-language (EFL) SILL data, concluded that the frequency of strategy use is related to language performance and that "more advanced or more proficient students use strategies more frequently." (p.10)

\section{Language Learning Strategies and Culture}

Research into strategies and culture verges on stereotyping. Asian students were found to differ from Hispanic students in their preference of rote memorization and rule-oriented strategies (Politzer \& McGroarty, 1985, cited in Grainger, 1997). Oxford (1994, cited in Grainger, 1997) found that Taiwanese students seem far more structured, analytic, memory based, and metacognitively oriented than other groups of learners. Spanish learners were found to use "traditional" strategies such as using dictionaries in learning words (McGroarty, 1987, cited in Oxford \& Burry-Stock, 1995). Whereas O'Malley and Chamot (1990) found that Asian students prefer rote learning strategies, Grainger (1997) found little difference in overall strategy use among Asian, English, and European students. The most interesting finding of Grainger was that students of Asian background, unlike what was asserted in previous studies, did not report preferring rote learning strategies.

\section{Purpose of the Study}

The present study attempts to add another set of data from the Arabian Gulf investigating the underlying factors of the SILL that may allow for further cross-culture comparisons. It further investigates the relationship between both gender and language level and the underlying factors of the SILL.

\section{Research Questions}

(1) What are the factors underlying the SILL given data collected from Kuwait?

(2) Are the identified factors in Kuwait similar to the factors obtained from other sets of data from different countries?

(3) Is there a significant relationship between gender and the identified factors?

(4) Is there a significant relationship between language level and the identified factors?

\section{Method}

\section{Sample}

The 750 subjects were randomly selected from students enrolled in the four colleges of the second leading educational in Kuwait, the Public Authority of Applied Education and Training (PAAET). The subjects were from four segregated colleges. These were College of Business studies, College of Basic Education, College of Technological Studies, and College of Health Sciences.

\section{Instrumentation}

The Arabic translation of the SILL was used (Kassabgy \& Boraie, 1992). The SILL developed by Oxford (1990) is now a well-established research tool widely used around the world. ${ }^{2}$

The SILL (version 7.0) comprises 50 items classified into six a priori strategy groups. The categories are based on Oxford's (1990) classification of language learning strategies as direct and indirect. The direct strategies are those used by learners to work with the language itself in different tasks. Those "include memory strategies for remembering and retrieving information, cognitive strategies for understanding and producing the language, and compensation strategies for using the language despite knowledge gaps" (Oxford, 1990, p. 37). Indirect strategies, on the other hand, are those used by learners for the management of learning. These include metacognitive strategies "for coordinating the learning process, affective strategies for regulating emotions, and social strategies for learning with others." (Oxford, 1990, p. 135)

\section{Data Collection Procedures}

Seven hundred fifty translated versions of the SILL were distributed in all colleges. Teachers were instructed to give the SILL to those students whose names were decided by the computer and written on the questionnaires. Five hundred and four students responded: 244 males and 260 females. The language proficiency of the subjects was determined on the basis of their enrollment in two levels of English courses. Students were assigned to these courses based on their performance on a placement test.

\section{Data Analysis}

The SILL includes six a priori categories comprising 50 items. Each category contains individual strategies classified as they relate to memory, metacognition, cognition, affection, compensation, and social interaction. Factor analysis, in a way, reclassifies these individual strategies belonging to separate categories resulting in new a posteriori categories (factors) comprising strategies related to one another despite their belonging to a priori categories.

In this study, an eight-factor Varimax factor analytic solution was used. Eigen values were required to be more than 1.0. To be included as part of a factor, the loading of any individual item should be more than .30. In addition, the $t$ test was used in order to test the relationship between gender, proficiency, and the identified factors. $P<.05$ was used to determine significance. 


\section{Results}

\section{Factor Analysis Results}

Unlike other sets of data from previous studies, eight variables instead of nine were identified. The identified factors and percentage of variance are shown in Table 1. Together, they explained $42.10 \%$ of the variability among the 50 items on the SILL.

Factor one. Active naturalistic use of English comprised some but not all of the individual strategies that loaded on the same factor in other studies. In Kuwait, this factor comprised (\#11) I try to talk like native English speakers, (\#13) I use English words in different ways, (\#14) I start conversations in English, (\#15) I watch TV and movies in English, (\#16) I read for pleasure, (\#17) I write notes and reports in English, (\#35) I look for people to talk to in English, (\#36) I look for opportunities to read as much as possible in English, (\#49) I ask questions in English, and (\#50) I try to learn about the culture of English speakers (See Table 2). Oxford and Burry-Stock (1995) coined the term "active naturalistic," and they used it to refer to language strategies not related to formal classroom learning of English. Given the cosmopolitan nature of Kuwait as a job market, Kuwaitis seemed to prefer the strategies that enable them to communicate with the multitude of nationalities living there and using English as their main means of communication. Factor One comprised cognitive, metacognitive, and social strategies all related to daily life practices away from formal language study. This finding provided critical evidence that the social context and the cultural milieu in which learners live may have more of an impact on their choice of strategies than ethnicity. It may be preferable to discuss strategy use not in terms of what an Arab student, a Spanish student, or an Indian student does or does not do but in terms of where each lives and the demands a surrounding context imposes on each. This point will be discussed in more detail at the end of the paper when a more contextualized approach to strategy research is proposed.

Factor two. This factor, labeled metacognitive planning (awareness-of-self strategies), was viewed in this study as more of thinking or focusing on self. Strategies loading on this factor seemed to describe learners' awareness of how they think about themselves, their progress, their feelings, and their becoming better learners (see Table 3).

Factor three. This factor comprised a combination of cognitive and compensation strategies (see Table 4). This factor was interesting in that the strategies comprising it were all concerned with vocabulary either in context or in isolation. This might be related to how vocabulary was being taught in these colleges. Vocabulary work occupied a great deal of attention, yet students were mostly given lists to memorize. This finding also suggested that the teaching context (a part of the larger social context) could also play a role in determining what strategies learners chose to adopt.

Factor four. This factor comprised strategies that involved some kind of physical action dealing with senses. Acting, preparing flashcards, summarizing or writing diaries all involve active, observable physical action for aiding memory. These types of strategies were labeled in this study as sensory-memory strategies (see Table 5).

Factors five and six. Factor five included strategies

Table 1

LIST OF FACTORS

\begin{tabular}{clc}
\hline Factor & Description & Percentage of variance \\
\hline 1 & Active naturalistic use of English & 16.20 \\
\hline 2 & Metacognitive planning & 5.54 \\
\hline 3 & Cognitive compensatory strategies & 4.63 \\
\hline 4 & Sensory-memory strategies & 3.81 \\
\hline 5 & Repetition-revision strategies & 3.49 \\
\hline 7 & Social strategies & 3.03 \\
\hline TOTAL & Affective strategies & 2.52 \\
\hline
\end{tabular}


involving practice, repetition, and revision (see Table 6), whereas factor six included social strategies involving practicing with others and asking for their help (see Table 7).

Factor seven. This factor consisted of affective strategies including attempts for relaxation, giving self a reward, and noticing when one is nervous (see Table 8).

Factor eight. This factor consisted of cognitive-memory strategies where learners attempt to draw mental images of the

\section{Table 2}

\section{FACTOR ONE: ACTIVE NATURALISTIC LANGUAGE USE}

\begin{tabular}{ll}
\hline Item & Loading \\
\hline $11(\operatorname{cog})$ I try to talk like native speaker & .545 \\
\hline $13(\operatorname{cog})$ I use English words I know in different ways & .477 \\
\hline $14(\operatorname{cog})$ I start conversations in English & .668 \\
\hline $15(\operatorname{cog})$ I watch TV and movies in English & .514 \\
\hline $16(\operatorname{cog})$ I read for pleasure in English & .609 \\
\hline $17(\operatorname{cog})$ I write notes, messages, letters, or reports in English & .503 \\
\hline $35(\mathrm{met})$ I look for people I can talk to in English & .533 \\
\hline $36(\mathrm{met})$ I look for opportunities to read as much as possible in English & .559 \\
\hline $49($ soc) I ask questions in English & .590 \\
\hline 50 (soc) I try to learn about the culture of English speakers & .445 \\
\hline Note: cog = cognitive strategies; met = metacognitive strategies; soc = social strategies
\end{tabular}

Table 3

FACTOR TWO: METACOGNITIVE PLANNING (AWARENESS-OF-SELF STRATEGIES)

\begin{tabular}{lc}
\hline Item & Loading \\
\hline 30 (met) I try to find as many ways as I can to use English & .411 \\
\hline 31 (met) I notice my English mistakes and use that information to help me do better & .574 \\
\hline 32 (met) I pay attention when someone is speaking English & .591 \\
\hline 33 (met) I try to find out how to be a better learner of English & .651 \\
\hline 37 (met) I have clear goals for improving my English & .434 \\
\hline 38 (met) I think about my progress in learning English & .577 \\
\hline 40 (aff) I encourage myself to speak English even when I am afraid of making a mistake & .396 \\
\hline Note: met = metacognitive strategies; aff = affective strategies
\end{tabular}


new English words in order to remember them, think of patterns, or translate word for word (see Table 9).

Factors related to gender. Males were found to use active naturalistic strategies (factor one) significantly more than females. Females, on the other hand, used cognitive-compensatory strategies (factor 3) and repetition and revision strategies (factor 5) significantly more than males (see Table 10).

Factors related to language level. Level Two students were found to use strategies of active naturalistic language use (factor one) more than Level One students did. Level One students, on the other hand, reported using affective strategies (factor seven) more than Level Two students did (see Table 11).

\section{Table 4}

\section{FACTOR THREE: COGNITIVE-COMPENSATORY STRATEGIES}

Item

\section{Loading}

9 (mem) I remember new English words or phrases by remembering their location on the page, on the board, or on a street sign

18 (cog) I first skim an English passage (read over the passage quickly) then go back and read carefully

$21(\operatorname{cog})$ I find the meaning of an English word by dividing it into parts that I understand

24 (com) To understand unfamiliar English words, I make guesses

25 (com) When I can't think of a word during a conversation in English,

I use gestures

26 (com) I make up new words if I do not know the right ones in English

28 (com) I try to guess what the other person will say next in English

29 (com) If I can't think of an English word, I use a word or phrase that means the same thing

Note: mem = memory strategies; $\operatorname{cog}=$ cognitive strategies; $c 0 m=$ compensatory strategies

\section{Table 5}

\section{FACTOR FOUR: SENSORY-MEMORY STRATEGIES}

\begin{tabular}{lc}
\hline Item & Loading \\
\hline 6 (mem) I use flashcards to remember new English words & .551 \\
\hline 7 (mem) I physically act out new English words & .498 \\
\hline 23 (cog) I make summaries of information that I read or hear in English & .447 \\
\hline 43 (aff) I write down my feelings in a language diary & .662 \\
\hline
\end{tabular}

Note: mem = strategies; $\operatorname{cog}=$ cognitive strategies; aff = affective strategies 
Table 6

\section{FACTOR FIVE: REPETITION-REVISION STRATEGIES}

\begin{tabular}{lcc}
\hline Item & Loading \\
\hline $\begin{array}{l}\text { (mem) I think of relationships between what I already know and } \\
\text { new things I learn in English }\end{array}$ & .330 \\
\hline 2 (mem) I use new English words in a sentence so I can remember them & .459 \\
\hline 3 (mem) I connect the sound of a new English word and an image or picture \\
$\begin{array}{l}\text { of the word to help me remember the word } \\
\text { (mem) I review English lessons often }\end{array}$
\end{tabular}

\section{Table 7}

\section{FACTOR SIX: SOCIAL STRATEGIES}

\begin{tabular}{lc}
\hline Item & Loading \\
\hline 46 (soc) I ask English speakers to correct me when I talk & .643 \\
\hline 47 (soc) I practice English with other students & .461 \\
\hline 48 (soc) I ask for help from English speakers & .713 \\
\hline Note: soc = social strategies &
\end{tabular}

Table 8

FACTOR SIX: AFFECTIVE STRATEGIES

\begin{tabular}{lc}
\hline Item & Loading \\
\hline 39 (aff) I try to relax whenever I feel afraid of using English & .642 \\
\cline { 1 - 2 } 41 (aff) I give myself a reward or treat when I do well in English & .484 \\
\hline 42 (aff) I notice if I am tense or nervous when I am studying or using English & .050 \\
\hline Note: aff = affective strategies &
\end{tabular}




\section{Discussion}

The results of the factor analysis were consistent with the findings of studies investigating strategies in foreign language contexts (People's Republic of China, Japan, and combined United States) and hybrid contexts (Puerto Rico). Active naturalistic language use was the number one factor explaining the most variability in the SILL. This find- ing supported an assumption adopted throughout this paper that social context is probably the strongest variable influencing subjects to use certain strategies more than others. Contexts rich with authentic input are perhaps more conducive to learners' use of naturalistic language learning strategies.

Gender differences in learning strategy use remain the

\section{Table 9}

\section{FACTOR EIGHT: COGNITIVE MEMORY STRATEGIES}

\begin{tabular}{lc}
\hline Item & Loading \\
\hline $\begin{array}{l}\text { (mem) I remember a new English word by making a mental picture of a } \\
\text { situation in which the word might be used }\end{array}$ & .368 \\
\hline $5(\mathrm{mem})$ I use rhymes to remember new English words & .386 \\
\hline $19(\operatorname{cog})$ I look for words in my own language that are similar to new words in English & .334 \\
\hline $20(\operatorname{cog})$ I try to find patterns in English & -.503 \\
\hline $22(\operatorname{cog})$ I try not to translate word for word & \\
\hline Note: mem = memory strategies; cog = cognitive strategies
\end{tabular}

\section{Table 10}

\section{FACTORS RELATED TO GENDER}

\begin{tabular}{|c|c|c|c|c|c|c|c|}
\hline \multirow[t]{2}{*}{ Factor } & \multicolumn{2}{|c|}{$\begin{array}{c}\mathrm{n}=244 \\
\text { Male }\end{array}$} & \multicolumn{2}{|c|}{$\begin{array}{l}\mathrm{N}=260 \\
\text { Female }\end{array}$} & \multirow{2}{*}{$\mathrm{T}$} & \multirow{2}{*}{ Sig } & \multirow{2}{*}{ Comment } \\
\hline & Mean & SE & Mean & SE & & & \\
\hline 1 & 3.25 & .046 & 3.11 & .045 & 2.107 & $.036^{*}$ & $M>F$ \\
\hline 2 & 4.04 & .044 & 4.06 & .041 & -.435 & .664 & \\
\hline 3 & 3.41 & .040 & 3.565 & .041 & -2.531 & $.012^{*}$ & $\mathrm{~F}>\mathrm{M}$ \\
\hline 4 & 2.04 & .047 & 2.006 & .046 & .575 & .565 & \\
\hline 5 & 3.48 & .045 & 3.671 & .037 & -3.216 & $.001^{*}$ & $\mathrm{~F}>\mathrm{M}$ \\
\hline 6 & 3.53 & .060 & 3.461 & .056 & .943 & .346 & \\
\hline 7 & 3.05 & .060 & 3.173 & .057 & -1.385 & .167 & \\
\hline 8 & 2.84 & .043 & 2.838 & .043 & .108 & .914 & \\
\hline
\end{tabular}

Note: $p<0.05$ 
Table 11

\section{FACTORS RELATED TO LANGUAGE LEVEL}

\begin{tabular}{|c|c|c|c|c|c|c|c|}
\hline \multirow[t]{2}{*}{ Factor } & \multicolumn{2}{|c|}{$\begin{array}{c}\mathrm{n}=208 \\
\text { Level } 1\end{array}$} & \multicolumn{2}{|c|}{$\begin{array}{c}\mathrm{N}=296 \\
\text { Level } 2\end{array}$} & \multirow{2}{*}{$\mathrm{T}$} & \multirow{2}{*}{ Sig } & \multirow{2}{*}{ Comment } \\
\hline & Mean & SE & Mean & $S E$ & & & \\
\hline 1 & 3.04 & .047 & 3.27 & .043 & -3.434 & $.001^{*}$ & Level 2 > Level 1 \\
\hline 2 & 4.03 & .047 & 4.06 & .039 & -.440 & .660 & \\
\hline 3 & 3.51 & .045 & 3.47 & .038 & .687 & .492 & \\
\hline 4 & 2.02 & .050 & 2.02 & .044 & -.122 & .903 & \\
\hline 5 & 3.53 & .047 & 3.60 & .038 & -1.131 & .259 & \\
\hline 6 & 3.56 & .059 & 3.45 & .056 & 1.346 & .179 & \\
\hline 7 & 3.25 & .064 & 3.02 & .054 & 2.749 & $.006^{*}$ & Level $1>$ Level 2 \\
\hline 8 & 2.84 & .048 & 2.84 & .039 & -.035 & .972 & \\
\hline
\end{tabular}

Note: $p<0.05$

most illusive. In a previous study (El-Dib, 1999a), there were no significant differences between males and females in using the six a priori categories of the SILL; memory, cognitive, metacognitive, compensatory, affective, and social strategies. In this study, the results of the $t$ test analysis showed that males use the strategies of factor one (active naturalistic language) significantly more than females do. Females, on the other hand, were found to use the strategies of factor three (cognitive-compensatory) and factor five (repetition-revision strategies) significantly more than males do. This discrepancy between the results of the first and the second study did not indicate female's use of more strategies than males. It rather suggested that the cultural milieu in which both males and females live and the opportunities given to each within that cultural context determined the types of strategies used by either sex.

The results suggest that a society or social context that is gender sensitive may play a role in females' adoption of strategies other than those adopted by males. Females in a conservative society where they may not have many opportunities to socialize with speakers of English may have classrooms as the only venue for using strategies to learn English. Males in such a society, on the other hand, exercise more freedom in traveling, socializing and, going to the movies which allows them to select naturalistic strategies.

The results indicating the tendency of less proficient students to use affective strategies in order to help them deal with tension related to learning a foreign language, reopens the issue of anxiety and its relationship to language acquisition. It poses questions regarding the relationship among anxiety, language learning, and learning strategies and whether or not the relationship is linear or cyclical in nature. In other words, would a student with limited proficiency exhibit more anxiety about his/her language learning and would this lead to more or less use of strategies? Would more use of strategies lead to less anxiety? Would use of certain strategies more than others lessen anxiety or increase it and would this increase or decrease learning? These questions call for further research in order to establish possible relationships between strategy use and a host of psychological variables such as anxiety, self-efficacy, and self-confidence (MacIntyre, 1994).

\section{Directions For Future Research}

The proposal made in this study regarding the significant role played by the contexts of language learning in the choice of learning strategies calls for research methodology that transcends the procedures of mass data collection. Questionnaires do not "typically provide detailed taskrelated information" (Oxford, 1996, p. 247), in spite of their efficiency in collecting data from large samples of learners. Using questionnaires reflects an approach to investigating strategy use that is separate from context. 
This approach is an interventionist rather than a descriptive (Okan, 2001), discovery-in-relation-to-task approach.

It is argued here that strategy use is probably a function of learning contexts and tasks rather than a function of gender, ethnic identity, or learning styles. Thus, the future direction of strategy research should be moving toward relating strategy use to the tasks and demands of learning contexts situated in a cultural milieu. It is not difficult to imagine a context where learners are deprived of natural (or authentic) language input outside of classrooms and how that might lead them to use particular strategies regardless of their gender or learning style. For example, learners performing the same types of tasks throughout a textbook especially in EFL contexts might prevent them from exploring different strategies needed to deal with the demands of new and different tasks.

Based on these proposals, think-aloud protocols, and retrospective verbal reports may be the most appropriate techniques for strategy assessment. These may be strengthened and supported by using video and audiotapes in order to help learners remember their thinking processes during their performance of given tasks (Anderson \& Vandergrift, 1996). Examples of research studies utilizing these techniques are Anderson (1991), Cohen (1987), Cohen and Olshtain (1993), and Murphy (1987).

Future studies may investigate the particularities of certain language learning tasks and contexts and how these may dictate or facilitate using certain strategies while blocking others. This in turn may help language educators think of ways to manipulate contexts of learning in order to help learners use a wider range of strategies and perhaps discover new ones.

\section{Acknowledgments}

The author would like to thank the anonymous Foreign Language Annals readers for their valuable comments on the earlier version of the manuscript.

\section{Notes}

1. Numbers indicate the strategies' numbers on the SILL (version 7.0).

2. For detailed information about the utility, reliability and validity of the SILL, refer to Oxford and Burry-Stock (1995).

\section{References}

Anderson, N.J. (1991). Individual differences in strategy use in second language reading and testing. Modern Language Journal, $75,460-472$.

Anderson, N.J. and Vandergrift, L. (1996). Increasing metacognitive awareness in the $\mathrm{L} 2$ classroom by using think-aloud protocols and other verbal report formats. In R. Oxford, (Ed.), Language learning strategies around the world: Cross-cultural perspectives (pp. 3-18). Honolulu, HI: University of Hawaii Press.
Cohen, A. D. (1987). Student processing of feedback on their compositions. In A. Wenden and J. Rubin (Eds.), Learner strategies in language learning (pp. 57-69). Englewood Cliffs, NJ: Prentice Hall.

Cohen, A. D. and Olshtain, E. (1993). The production of speech acts by EFL learners. TESOL Quarterly, 27, 33-56.

El-Dib, M. A. (1999a). Male/female differences in language learning strategies reconsidered. Journal of the Faculty of Language and Translation Studies, AL Azhar University, 30, $1-24$.

El-Dib, M. A. (1999b). Language learning strategies: A view from the Arabian Gulf. Journal of Mansoura Faculty of Education, 40, 49-77.

Grainger, P. (1997). Language-learning strategies for learners of Japanese: Investigating ethnicity. Foreign Language Annals, 30, 378-385.

Green, J. and Oxford, R. L. (1995). A closer look at learning strategies, L2 proficiency, and gender. TESOL Quarterly, 29, 261-297.

Govier, E. (1998). Brain sex and occupation. In J. Radford, (Ed.), Gender and choice in education and occupation (pp. 1-17). London: Routledge.

Holec, H. (1987). The learner as manager: Managing learning or managing to learn? In A. Wenden and J. Rubin, (Eds.), Learner strategies in language learning (pp. 145-158). Englewood Cliffs: NJ: Prentice Hall.

Kassabgy, O. and Boraie, D.(1992). (Trans.) Strategy Inventory of Language Learning .

Kaylani, C. (1996). The influence of gender and motivation on EFL learning strategy use in Jordan. In R. Oxford (Ed.), Language learning strategies around the world: Cross-cultural perspectives (pp. 75-88). Honolulu, HI: University of Hawaii Press.

Kuwait Information Office-USA. (2002). People [online]. Available:http://www.kuwait-info.org/Country_Profile/land_and_ people/people.html

Library of Congress Country Studies. (1993). Kuwait Society [online].Available:http://lcweb2.loc.gov/cgi-bin/ query/r?frd/cstdy:@field(DOCID+kw0027)

MacIntyre, P. (1994). Toward a social psychological model of strategy use. Foreign Language Annals, 27, 185-195.

Murphy, J. M. (1987). The listening strategies of English as a second language college students. Research and Teaching in Developmental Education, 4, 27-46.

Okan, Z. (2001). A constructivist view on learning strategies. Poster session presented at the Second International Conference on Contrastive Rhetoric, The American University, Cairo.

O'Malley, J. M. and Chamot, A. U. (1990). Learning strategies in second language acquisition. Cambridge: Cambridge University Press.

Oxford, R. (1989). Use of language learning strategies: A synthesis of studies with implications for strategy training. System, 17, 235-247.

Oxford, R. (1990). Language learning strategies: What every teacher should know. Boston: Heinle \& Heinle.

Oxford, R. (1996). Afterword. What have we learned about 
language learning strategies around the world? In R. Oxford (Ed.), Language learning strategies around the world: Cross-cultural perspectives (pp. 247-249). Honolulu: University of Hawaii Press.

Oxford, R. and J. Burry-Stock. (1995). Assessing the use of language learning strategies worldwide with the ESL/EFL version of the Strategy Inventory for Language Learning (SILL). System, 23, 1-23.

Oxford, R., Park-Oh, Y., Ito, S. and Sumrall, M. (1993). Japanese by satellite: Effects of motivation, language learning styles and strategies, gender, course level, and previous language learning experience on Japanese language achievement. Foreign Language Annals, 26, 359-371.
Politzer, R. L. (1983). An exploratory study of self reported language learning behaviors and their relation to achievement. Studies in Second Language Acquisition, 6, 54-68.

U.S. Commercial Service-Kuwait. (2003.) Language [online]. Available: http://www.buyusa.gov/kuwait/en/index.php?page= 201\&print $=1$

Vandergrift, L. (1997). The comprehension strategies of second language (French) listeners: A descriptive study. Foreign Language Annals, 30, 386-409. 